\title{
Formation, Influence Mechanism and Experimental Characterization of Composite Porosity
}

\author{
Li Shujian', $\quad$ Zhan Lihua ${ }^{1}, \quad$ Chen Rong ${ }^{2}, \quad$ Zeng Liran', $\quad$ Zhou Yuanqi $^{1}$ \\ ${ }^{1}$ Central South University, Changsha 410083, China; ${ }^{2}$ Hunan Institute of Engineering, Xiangtan 411101, China
}

\begin{abstract}
In view of the common issue of composite porosity, the formation and influence mechanism of composite porosity were elucidated from the aspects of mechanical mixed nucleation theory and classic nucleation theory, and the characterization of porosity morphology, distribution and size were conducted through specific experiments. Results show that poor wettability of fibers, retention of vapor molecules and molecular volatilization generated during crosslinking reaction are the main reasons of porosity formation. The lower cure pressures have little effect on eliminating the porosity. With the increase of cure pressure, the porosity factor and porosity size decrease significantly. There is a power function relation of three times among porosity factor, porosity diameter and cure pressure.
\end{abstract}

Key words: composite; porosity; influence mechanism; experimental characterization

Compared with traditional materials, advanced composites are nowadays widely used in the aerospace field due to their many features, such as high specific strength and stiffness, powerful designability, excellent resistance to fatigue fracture and corrosion resistance, and super structural stability so as to form large areas ${ }^{[1,2]}$. In the process of composite formation, manufacturing defects are apt to occur owing to the complexity of manufacturing environment, artificial error, process conditions and structural design. These defects may also have some serious effects on the mechanical properties and fatigue properties of materials, even cause component scrapped and costs of production wasted. Delamination, porosity and pore are the common defects during composite fabrication, but to some extent, the delamination and pore are related to porosity closely. Therefore, studying the formation and influence mechanism of composite porosity will have a great practical significance.

The present paper starts with the type and formation mechanism of porosity and elucidates the formation and diffusion mechanism of porosity. By designing a specific experiment, the morphology, size and distribution of porosity as well as the influence mechanism of cure pressures on them were tested through experimental characterization. Under certain conditions of environment, heating process and manufacturing structure type, as the main factor of defects, the influence of cure pressure on composite structural was pointed out. Moreover, the experimental data were fitted using the non-linear fitting method. The specific function relations among cure pressure, porosity factor and porosity size were revealed, which provide a theoretical and experimental support for optimizing the design of composite manufacturing process.

\section{Porosity Mechanism}

\subsection{Porosity types, forming and eliminating process}

Porosity is generally divided into fiber porosity (which is along the single fiber or located in fibers) and inter-porosity. Usually, the porosity is columnar shape when porosity is less than $1.5 \%$, while when the porosity is greater than $1.5 \%$ it is cylindrical shape, and the porosity is generally parallel to the fiber axial direction. Three main reasons of porosity formation are as follows ${ }^{[3,4]}$. Firstly, poor wettability makes the air or water vapor hard to exclude. Secondly, volatilization of low

Foundation item: National Key Basic Research Development Program of China (“973” Program)(2014CB046502); Fundamental Research Funds for the Central Universities of Central South University (2014zzts036); Hunan Postdoctoral Scientific Program (2014RS4013); China Postdoctoral Science Foundation (2014M562127); Open Fund of Key Laboratory of High Performance Complex Manufacturing of Central South University (Kfkt2013-04)

Corresponding author: Zhan Lihua, Ph. D., Professor, Light Alloys Research Institute, Central South University, Changsha 410083, P. R. China, Tel: 0086-731-88830254, E-mail: yjs-cast@csu.edu.cn 
molecule is detained in the resin. Thirdly, the chemical reaction volatiles are generated in the curing process of resin. In addition, with the variation of different processing parameters such as curing process temperature, pressure, time and resin viscosity, the appearance of porosity also changes.

According to the Loos and Springer ${ }^{[5]}$ flow-compaction model, for the composite laminate structure, the flow direction of resin is mainly along the vertical direction of the thickness and parallel to fiber axial direction. Simultaneously, the bubbles are excluded at high system pressures. The process of porosity formation and removal is shown in Fig.1.

\subsection{Forming mechanism of porosity}

As for the issue of porosity formation in composite, the influence factors and forming mechanism are extremely complicated, which is the results of combined effect of process conditions, type of resin, fiber arrangement method and environmental humidity. From the aspects of mechanical mixed nucleation theory and classic nucleation theory, Springer ${ }^{[5]}$ and $\operatorname{Kardos}^{[3]}$ analogized the formation mechanism of composite porosity, which become a basis to study the formation mechanism of porosity.

\subsubsection{Mechanical mixed nucleation theory}

The mechanical mixed nucleation theory holds that any spherical nucleus of diameter $d_{i}$ is assumed to exist in the prepreg. Water vapor caused by environmental humidity is filled in the nucleus, and the internal pressure of nucleus $P_{\mathrm{wi}}$ can express by Eq. (1):

$$
P_{\mathrm{wi}}=\Phi_{\mathrm{a}} P_{\mathrm{wga}}
$$

where, $P_{\mathrm{wga}}$ is the saturation pressure of the water vapor at the ambient temperature, and $\Phi_{\mathrm{a}}$ is the environmental humidity.

In the curing process, water and other types of molecules transport across the prepreg-porosity interface. The pressure at the location of porosity increases as the cure pressure increases, which all increase the volume of porosity. The internal pressure of porosity $P_{\mathrm{V}}$ can be expressed by Eq. (2):

$$
P_{\mathrm{v}}-P=\frac{4 \sigma}{d_{i}}
$$

where, $P$ is the pressure surrounding the porosity, and $\sigma$ is the surface tension between the resin and the porosity.

The liquid in the porosity mainly consists of water vapor and volatiles generated during curing reaction. Therefore, the internal

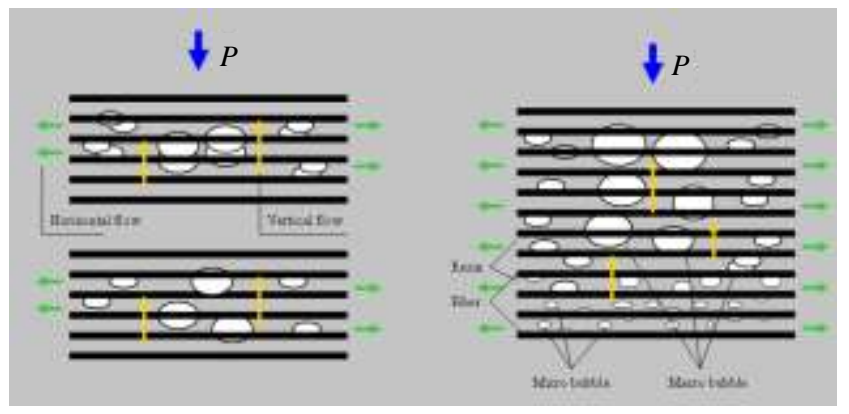

Fig.1 Process of bubbles formation and removal pressure of porosity can be also expressed as Eq. (3):

$$
P_{\mathrm{V}}=P_{\text {wi }}+P_{\text {air }}
$$

where, $P_{\mathrm{wi}}$ and $P_{\text {air }}$ are the partial pressures of the water vapor and the air in the porosity, respectively. The partial pressure is a known function of temperature, mass and porosity diameter, as can be shown in Eqs. (4) and (5):

$$
\begin{aligned}
& P_{\mathrm{wi}}=f\left(T, m_{\mathrm{wi}}, d_{i}\right) \\
& P_{\text {air }}=f\left(T, m_{\mathrm{air}}, d_{i}\right)
\end{aligned}
$$

\subsubsection{Classic nucleation theory}

It is assumed that the critical-size nuclei of porosity may be formed from ideal vapor at a rate $I$, and the rate of homogeneous nucleation $I$ can be expressed as Eq. (6):

$$
I=\left[\frac{P}{(2 \pi M k T)^{1 / 2}}\right] 4 \pi r^{2} n \exp \left[\frac{-\Delta F}{k T}\right]
$$

where, $P$ is the total mixture pressure, $M$ is the molecular weight of the vapor phase, $k$ is the Boltzmann constant, $T$ is the absolute temperature, $r$ is the radius of critical nucleus, $n$ is the number of molecules and $\Delta F$ is the maximum free energy barrier for the nucleation process.

The $\Delta F$ and $r$ are given by Eqs. (7) and (8):

$$
\begin{aligned}
& \Delta F=\frac{16 \pi \gamma_{\mathrm{LV}}^{3}}{3\left(\Delta F_{\mathrm{V}}\right)^{2}} \\
& r=-\frac{2 \gamma_{\mathrm{LV}}}{\Delta F_{\mathrm{V}}}
\end{aligned}
$$

$\Delta F_{\mathrm{V}}$ is the free energy change per unit volume for the phase transition, and $\gamma_{\mathrm{LV}}$ is the surface energy between the liquid resin and the pore nucleus. $\Delta F_{\mathrm{V}}$ is given by Eq. (9):

$$
\Delta F_{\mathrm{V}}=\Delta H_{\mathrm{v}}\left(\frac{T_{0}-T}{T_{0}}\right)
$$

where, $\Delta H_{\mathrm{V}}$ is the heat of transition per unit volume between the two phases, $T_{0}$ is the equilibrium transition temperature, and $T$ is the actual temperature of the system.

When the porosity are formed and in a stable state, the internal pressures between porosity $P_{\mathrm{g}}$ and resin $P_{\mathrm{e}}$ can be given by Eq. (10):

$$
P_{\mathrm{g}}-P_{\mathrm{e}}=\frac{\gamma_{\mathrm{LV}}}{m_{\mathrm{LV}}}
$$

$\gamma_{\mathrm{LV}}$ is the surface tension between resin and porosity, and $m_{\mathrm{LV}}$ is the ratio of porosity volume to its surface area. If the nucleus of porosity is spherical, the Eq. (10) can be described as Eq. (11):

$$
P_{\mathrm{g}}=P_{\mathrm{e}}+\frac{6 \gamma_{\mathrm{LV}}}{d_{\mathrm{V}}}
$$

\section{Experimental Characterization}

It can be concluded from Eqs. (2) and (11), no matter what kind the nucleation mechanism is, it is closely related to the internal pressure of porosity and the external resin bearing pressure. While according to Springer resin flow-compaction 
model, the external resin matrix bearing pressure is transmitted by system cure pressure. Therefore, under certain conditions of manufacturing environment, ways of lay-up, component structure and curing temperature process, studying the effects of cure pressure on porosity becomes the key point of optimizing composite forming process.

\subsection{Materials}

The experimental composite used in the research is YPH-23/T700 epoxy prepreg (purchased from Yubo Composites Co., Ltd. China). The resin is a solvent-free epoxy resin which has a high thermal variation and impact resistance, especially developed for carbon fiber or glass fiber prepreg manufacturing.

\subsection{Fabrication of composite laminates}

The autoclave molding process was used to fabricate composite laminates. In order to measure the effects of cure pressure on composite porosity, the different system cure pressures were applied under certain conditions of manufacturing environment, ways of lay-up, component structure and curing temperature process (range of $0.0 \sim 0.6$ $\mathrm{MPa}$, the process interval was $0.1 \mathrm{MPa}$ ). 20 plies $[0]_{10 \mathrm{~s}}$ of each plate was designed and manufactured by manual paving for each cure route considered. The designed laminates dimension was $300 \mathrm{~mm}$ (length) $\times 200 \mathrm{~mm}$ (width) $\times 2 \mathrm{~mm}$ (thickness), and the final thickness was approximately $2.0 \sim 2.2 \mathrm{~mm}$ after curing. The specific process routes are shown in Fig.2.

\subsection{Optical digital microscopy observation}

For each piece of composite laminates cured at different pressures, samples were taken as $10 \mathrm{~mm} \times 10 \mathrm{~mm}$. According to the national standard GB3365-82, the samples were mosaic, polished, polishing and ultrasonic cleaning. The optical digital microscope (ODM, model: OLYMPUS DS $\times 500)$ and metallurgical microstructure image analysis systems were employed to study the microscopic structure of composite laminates.

\subsection{Porosity test}

The porosity was mainly calculated according to Eq. (12):

$$
V_{\mathrm{v}} \%=100-\rho_{\mathrm{c}} \cdot \frac{w_{\mathrm{r}}}{\rho_{\mathrm{r}}}+\frac{w_{\mathrm{f}}}{\rho_{\mathrm{f}}}
$$

where, $V_{\mathrm{V}} \%$ is percentage of porosity volume, $w_{\mathrm{r}}$ and $w_{\mathrm{f}}$ are mass percentage of resin and fiber, respectively. $\rho_{\mathrm{r}}$ and $\rho_{\mathrm{f}}$ are the density of resin and fiber, respectively. $\rho_{\mathrm{c}}$ is the density of carbon plate. The porosity sizes of different areas were measured in the microstructure image, and then the average value was taken as the average porosity diameter.

\section{Results and Discussion}

\subsection{Microstructure characterization of composite}

The microstructure of composite laminates formed under different autoclave pressures was analyzed by optical digital microscope. The porosity state of composite laminates located in the transverse and longitudinal section are shown in Fig.3 and Fig.4, respectively. Results show that when the cure

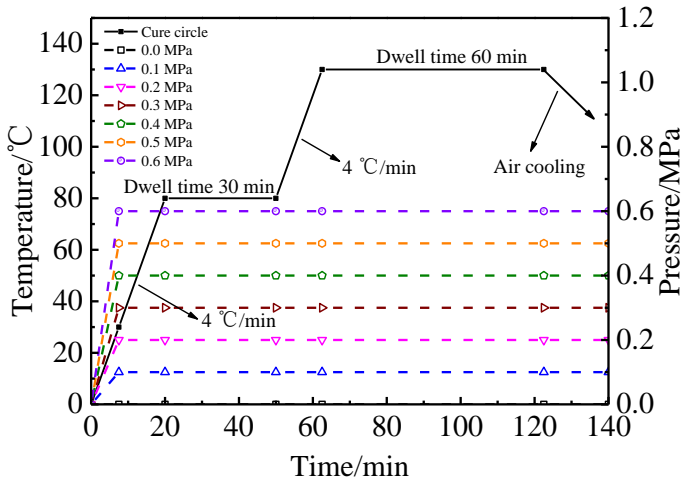

Fig.2 Plot of temperature versus time and pressure

pressure is lower than $0.2 \mathrm{MPa}$, the microstructure is far from ideal, porosity is large in size and number in the laminate. As can be seen from the longitudinal section of Fig.4a, porosity mainly distributes in the resin or attaches to the fiber-resin interface, and local delamination appears. This is due to the elimination of path of porosity, including the ways along the fiber arrangement direction and perpendicular to the surface of the fiber layer. On the one hand, under conditions of low system pressure, the poor flowability of resin and uneven distribution of the fibers in the thickness direction, which lead to incomplete infiltration of fibers, even cause delamination. On the other hand, although the infliction of pressure is helpful to the porosity elimination along the fiber direction, the removal of porosity is not ideal in the center area of laminate owing to the size of composite laminates; some bubbles are trapped in the resin matrix and the cylindrical porosity forms. Moreover, the pressure applied during the curing process will prevent the bubbles removal located in the direction perpendicular to fibrous layer. While a lower pressure cannot make sure the volatile content dissolve completely, and circular air bubbles may form inside the resin. According to Henry's law:

$$
M_{\text {gas }}=\text { mole }_{\text {gas }} / \text { liter }_{\text {solvent }}=k_{\text {gas }} \cdot P_{\text {gas }}
$$

$M_{\text {gas }}$ is the gas concentration in the solution, $P_{\text {gas }}$ is the gas pressure, and $k_{\text {gas }}$ is the solubility constants, which is concerned with gases and solvents. Hence, a larger system pressure is helpful to improve the resin flowability and solubility of the gas in the resin. From Fig.3 we can see that with the increase of the system pressure, the number and size of porosity decline sharply. When the system pressure is higher than $0.2 \mathrm{MPa}$, the microscopic structure of the composite tends to be uniform.

\subsection{Quantitative relation characterization}

Porosity factor and porosity size decrease with the system pressure increasing, which has been found by many scholars ${ }^{[6-9]}$. However, the specific functional relations among them are not systematic. For the experimental composite, the functional relations between porosity and cure pressure were measured using a non-linear fitting method, and the results are shown in 


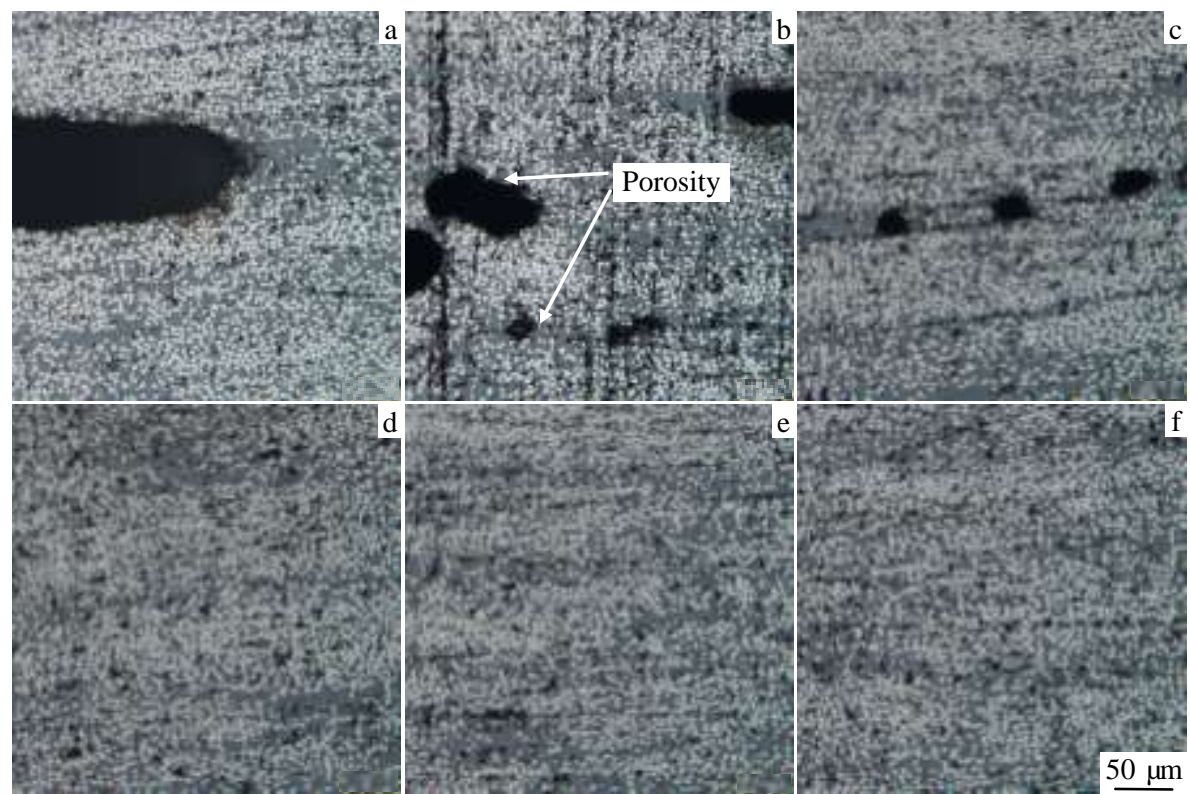

Fig.3 ODM morphologies of transversal surface with different cure pressures: (a) $0.0 \mathrm{MPa}$, (b) $0.1 \mathrm{MPa}$, (c) $0.2 \mathrm{MPa}$, (d) $0.4 \mathrm{MPa}$, (e) $0.5 \mathrm{MPa}$, and (f) $0.6 \mathrm{MPa}$

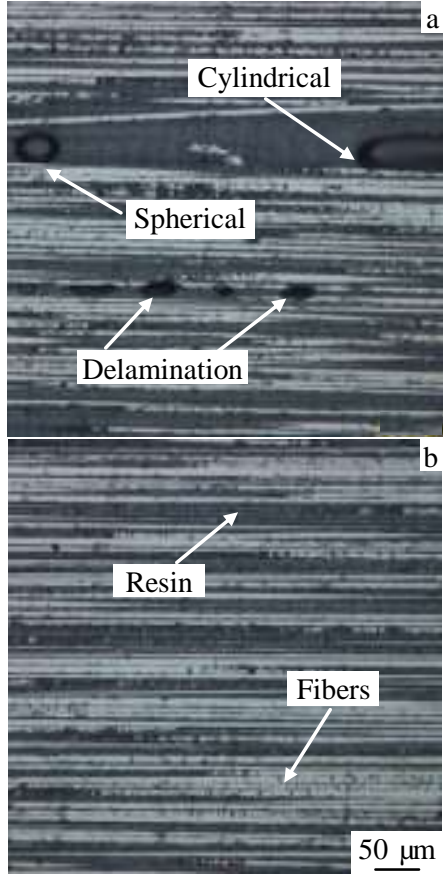

Fig.4 ODM morphologies of longitudinal section with different cure pressures: (a) $0.0 \mathrm{MPa}$ and (b) $0.6 \mathrm{MPa}$

Fig.5 and Fig.6. As can be seen from the results, the experimental data are in good agreement with the fitted curve, and the relations of three times power function exist among the porosity factor, pore diameter and cure pressure. The functional relations can be expressed by the following equations:

$f_{\text {porosity }}=5.37394-26.14617 p_{\text {cure }}+70.82995 p_{\text {cure }}^{2}-67.19472 p_{\text {cure }}^{3}(\%)$

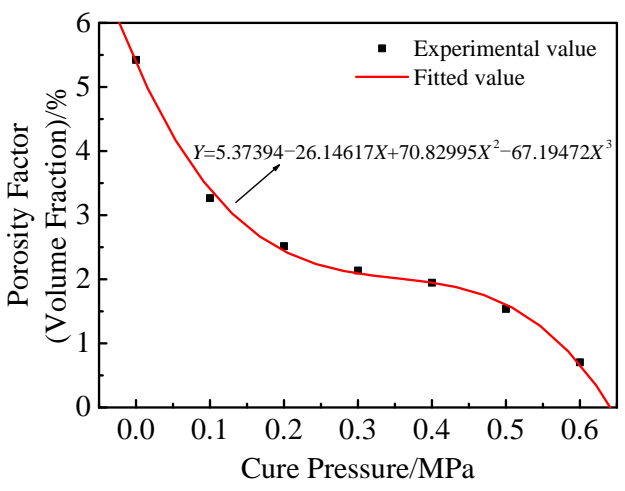

Fig.5 Plot of porosity factor versus cure pressure

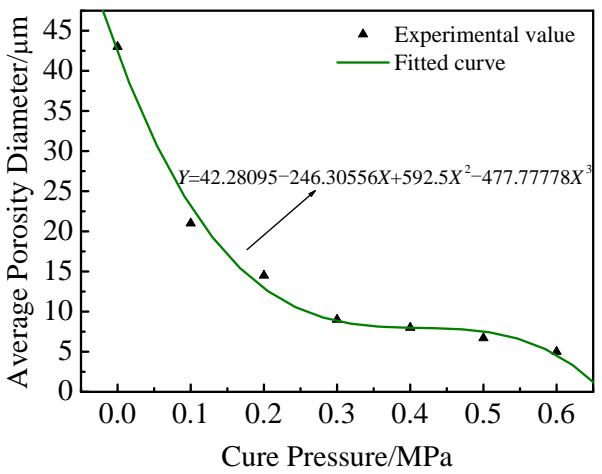

Fig.6 Plot of average porosity diameter versus cure pressure

$f_{\text {diameter }}=42.28095-204.30556 p_{\text {cure }}+592.5 p_{\text {cure }}^{2}-477.77778 p_{\text {cure }}^{3}(\mu \mathrm{m})$ The first curve inflection point occurs when the system pressure is applied to $0.2 \mathrm{MPa}$, but with the increase of cure pressure, the actual variation value of porosity factor and 


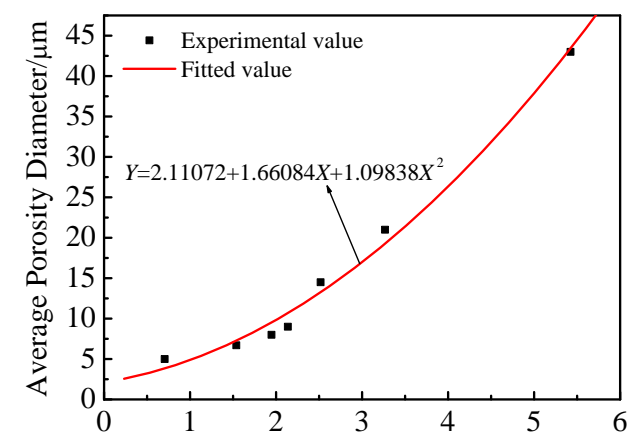

Porosity Factor of Different Cure Pressures/\%

Fig.7 Plot of average porosity diameter versus porosity factor

porosity diameter change a little. This is mainly because the air bubbles dissolve in the resin gradually to saturate with the increase of cure pressure.

It is interesting that the porosity diameter also increases with the porosity factor increasing, and the functional relation is shown in Fig.7, which further explains how the cure pressure affects composite porosity. Some scholars ${ }^{[10,11]}$ have found that the material strength and modulus change a little or even can be negligible when the porosity factor is $3 \% \sim 4 \%$. Another study ${ }^{[12]}$ suggested that porosity of $1 \% \sim 4 \%$ was a watershed change in the mechanical properties of composite. From microscopic structure, these points mentioned above are also consistent with the experimental results. Thus, the system pressure of $0.2 \mathrm{MPa}$ is the dividing value of material structure and performance changing. The cure pressure should be selected higher than $0.2 \mathrm{MPa}$.

\section{Conclusions}

1) The mechanical mixed nucleation theory and the classic nucleation theory all point out that the pore size and numbers are closely related to the system pressure under certain condition of other processes.
2) Low cure pressure (inferior to $0.2 \mathrm{MPa}$ ) has a little effect on eliminating the porosity in composite. With the increase of cure pressure, the porosity and porosity size decrease significantly, and the cure pressure should be selected higher than 0.2 MPa.

3) For the experimental material, the porosity factor, pore diameter and cure pressure have a relation of three times power function. The functional relations can be expressed by the following equations:

$$
\begin{aligned}
& f_{\text {porosity }}=5.37394-26.14617 p_{\text {cure }}+70.82995 p_{\text {cure }}^{2}-67.19472 p_{\text {cure }}^{3}(\%) \\
& f_{\text {diameter }}=42.28095-204.30556 p_{\text {cure }}+592.5 p_{\text {cure }}^{2}-477.77778 p_{\text {cure }}^{3}(\mu \mathrm{m})
\end{aligned}
$$

\section{References}

1 Chen Xiangbao. Journal of Aeronautical Materials[J], 2000, 1: 46

2 Hernández S, Sket F, Molina-Aldareguía J M et al. Composites Science and Technology[J], 2011, 71: 1331

3 Kardos J L, Dudukovic M P, Dave R. Advance in Polymer Science[J], 1986, 80: 105

4 Boey F Y C, Lye S W. Composites[J], 1992, 23: 262

5 Loos A C, Springer G S. Journal of Composite Materials[J], 1983, 17: 147

6 Wen Binyoung. Composites Science and Technology[J], 1995, 54: 299

7 Liu ling, Zhang Boming, Wang Dianfu et al. Composite Structures[J], 2006, 73: 308

8 Olivier P, Cottu J P, Ferret B. Composites[J], 1995, 26: 513

9 Su Shulan, Rao Qiuhua, He Yuehui. Rare Metal Materials and Engineering[J], 2014, 43(5): 1258 (in Chinese)

10 Michelle L C, Morable C R. Composites Science and Technology[J], 2001, 61: 2106

11 Alneida S F M, Nogueira N Z S. Composite Structures[J], 1994, 28: 142

12 Jeong H, Hsu D K. Ultrasonics[J], 1995, 33: 199

\title{
复合材料孔隙形成机理、影响机制及实验表征
}

\author{
李树健 ${ }^{1}$, 湛利华 ${ }^{1}$, 陈 蓉 $^{2}$, 曾理然 ${ }^{1}$, 周源琦 ${ }^{1}$ \\ (1. 中南大学, 湖南 长沙 410083) \\ (2. 湖南工程学院, 湖南 湘潭 411101)
}

\begin{abstract}
摘 要: 针对常见的复合材料孔隙问题, 从机械夹杂形核理论与经典形核理论分析了孔隙的形成与影响机制, 并通过具体实验对孔隙形 貌、分布、大小进行了表征。结果表明: 纤维浸润性差、蒸气分子的滞留及交联反应时的分子挥发是孔隙形成的主要原因; 较低固化压 力条件 (0.0 0.2 MPa), 对复合材料内部孔隙的消除作用不大, 随固化压力提高, 复合材料孔隙率及孔隙大小下降明显; 孔隙率、孔隙 大小与系统压力存在幂函数递减变化关系。
\end{abstract}

关键词：复合材料; 孔隙; 影响机制; 实验表征

作者简介: 李树健, 男, 1982 年生, 博士, 中南大学轻合金研究院, 湖南 长沙 410083, 电话: 0731-88830254, E-mail: smart0110@126.com 